\title{
Numerical simulation of Effect of Contact Pressure on Gas Diffusion Layers deformation of a PEM Fuel Cell
}

\author{
A. ATIFI, K. EI BIKRI, M. ETTOUHAMI \\ adilatifi@ research.emi.ac.ma
}

\section{Centre de Recherches en Sciences et Technologies de l'Ingénieur et la Santé, E2SN ENSET, Mohammed.V University of Rabat, Morocco}

\begin{abstract}
In this study, a two-dimensional, Finite Element model has been implemented based numerical modeling simulations to predict mechanical behavior of a representative unit of fuel cell stack deformation under three levels of contact pressure between GDL and bipolar plate assuming that the GDL deformation as a combination of elastic deformation and fibers slippage. The intrusion of the GDL into the channel was estimated. Indeed, with orthotropic behavior of the GDL, the proposed nonlinear orthotropic model converges towards the models of the literature as a function of the contact pressure level between the bipolar plate and the GDL (Gas Diffusion Layers).
\end{abstract}

Keywords: Fuel Cell, PEMFC, GDL intrusion, Stress, PFSA membrane, clamping force

\section{Introduction}

A Proton Exchange Membrane Fuel Cell is a mechanically constrained stack composed of several heterogeneous elements (Y. Faidi. 2016[1]). The risk of thermo-mechanical damage to the gas diffusion layers and the membrane is very likely because they are very thin and fragile. As the fuel cell stack is a multi-contact of elements in series, the damage of a single element can lead to the malfunction of the whole stack (Z. Zhang. 2010[2]). Moroever, contact pressure heterogeneity and internal mechanical stress between the assembly elements of a fuel cell causes large deformations, in particular in the gas diffusion layer (GDL), resulting in significant changes in its mechanical, electrical and thermal characteristics. The inhomogeneous compression of the GDL leads to several opposing effects. An insufficient clamping pressure may result in sealing problems, such as high contact resistance and fuel leakage (S. Lee et al. 2005[3]), which cause not only performance losses but also lead to potentially dangerous situations (G. Jibian. 2006[4]). On the other hand, excessive assembly pressures may squeeze the relative thin (GDL) and membrane, leads to destroy their pore al.2009 [5]).

On the other hand, as GDL intrusion in the channel is one of consequences of the inhomogeneous contact pressure between GDL and bipolar plate. This phenomenon, reduces the hydraulic diameter of the reactive gas channels, a direct consequence of the GDL intrusion into the channel can be seen as an increase in the inlet gas pressure drop, making it more difficult to discharge liquid water out of the channel (G. Maranzana et al.2008 [6], S. Basu et al.2009 [7]). Modeling approaches for describing machanical behaviour of the GDL have not been well developed and validated in comparison with experimental results. There still exists a gap between experimentally investigated finding and theoretical understanding. The numerical results show that the linear isotropic models are widely adopted in the literature ( [8], [9], [10]).Some mechanical modelling of the GDL use nonlinear isotropic models, or even piecewise linear isotropic models (P. Zhou. 2006[11]). Other study was presented by P. Zhou et al. 2007 [12], assuming quasi-isotropic models, where an orthotropic structural model for the GDL is adopted, but the shear modulus is calculated using a solely isotropic relation according to the report of Freunberger et al. [13].

\section{Model description}

The mechanical behavior of a whole PEMFC stack is assimilated to the one of its unit cells (O. Kyeongmin. 2014[15]) where a fixed displacement condition was applied to the end plate. Figure. 1 shows the size of the computational domain that is reduced to a typical unit cell of a PEMFC which is made of a membrane sandwiched between two electrodes gas diffusion layers assembly (GDE) (Y.Tang.2006[9]). The proposed model is based on the FEM method for the plane stress mechanical structural module with thermal expansion using the commercial Comsol Multiphysic's software. On the other side, the total thickness reduction of the GDL has been modeled as a combination of elastic deformation and slippage of carbon fibers (E.Sadeghi. 2011 [16]).

$$
\varepsilon_{y}=0.449\left(1-\exp \left(-1.0663 * P_{\text {contact }}\right)\right.
$$

$\mathrm{P}_{\text {cobtact }}$ is the contact pressure between bipolar plate and GDL 

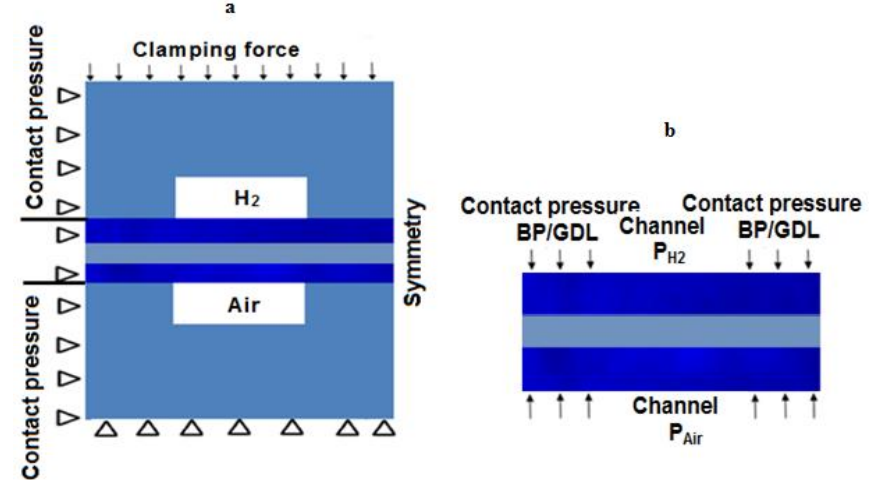

Figure.1 Schematic representations of typical single cell (a) and computational domain for FEM simulation (b)

Table.1 Geometric parameters for the multiphysics performances model

\begin{tabular}{|ll|}
\hline Paramètre & Valeur \\
\hline Membrane thickness & $50 \mu \mathrm{m}$ \\
Electrodede thickness & $10 \mu \mathrm{m}$ \\
GDL thickness & $190 \mu \mathrm{m}$ \\
Land width & $1 \mathrm{~mm}$
\end{tabular}

Mechanical deformations are presented with respect to the previous works model assuming non linear orthotropic behavior of GDL. The results will be compared with the work carried out by linear orthotropic model deduced by Kleemann and Y. Lai [17] and S.G. Kandlikar et al. [8] based on experimental measurements of the intrusion of GDL into the reagent channel. Similarly, during the validation process of our proposed model, we will also implement the nonlinear mechanical behavior of the GDL in the transverse direction by making a comparison with the model of PAG.Salaberri.2011 [18], based on the polynomial fit of the nonlinear compression modulus $\mathrm{E}_{\mathrm{y}}$ $\left(\varepsilon_{y}\right)$ found by M.Mathias [19]).

The membrane used in the model is the Nafion perfluorosulphonic acid of Dupont de Nemours N112. In the context of linear elasticity, we assume that the total deformation tensor is the sum of the contribution of mechanical and hygrothermal deformations (Y.Tang. 2006 [9]).

Table.2 GDL-TORAY-60 properties

\begin{tabular}{|c|c|c|c|c|c|}
\hline $\begin{array}{l}\text { Mod } \\
\text { el }\end{array}$ & $\begin{array}{c}\text { Non } \\
\text { linear } \\
\text { orthotrop } \\
\text { ic } \\
\text { of } \\
\text { Salaberri }\end{array}$ & $\begin{array}{l}\text { Non } \\
\text { linear } \\
\text { orthot } \\
\text { ropic } \\
\text { of Y. } \\
\text { Lai. }\end{array}$ & $\begin{array}{c}\text { Isotropic } \\
\text { Kandlikar2 } \\
009\end{array}$ & $\begin{array}{c}\text { Linear } \\
\text { orthotropic } \\
\text { ofJ.Kleeman } \\
\text { n. }\end{array}$ & $\begin{array}{c}\text { Non linear } \\
\text { orthotropic } \\
\text { proposed } \\
\text { model }\end{array}$ \\
\hline & GDL & GDL & GDL & GDE & GDE \\
\hline $\mathrm{E}_{\mathrm{x}}$ & 7Gpa & $\begin{array}{c}0.3 \mathrm{Gp} \\
\mathrm{a}\end{array}$ & $18 \mathrm{Mpa}$ & $1000 \mathrm{Mpa}$ & $1000 \mathrm{MPa}$ \\
\hline $\mathrm{E}_{\mathrm{z}}$ & 7Gpa & $\begin{array}{c}0.9 \mathrm{Gp} \\
\mathrm{a}\end{array}$ & $18 \mathrm{Mpa}$ & $1000 \mathrm{MPa}$ & $1000 \mathrm{MPa}$ \\
\hline $\begin{array}{l}E_{y} \\
\left(\varepsilon_{y}\right)\end{array}$ & $\begin{array}{c}\mathbf{1 4 . 1 7 5} \\
0.47<\varepsilon \leq 0 \\
.135\end{array}$ & $\begin{array}{l}11.67 \\
0.27< \\
\varepsilon \leq 0.2\end{array}$ & $18 \mathrm{Mpa}$ & $20 \mathrm{MPa}$ & $\mathrm{E}_{\mathrm{y}}\left(\mathrm{P}_{\mathrm{c}}\right)$ \\
\hline $\mathrm{G}_{\mathrm{xy}}$ & 18.5 & $\begin{array}{c}1 \\
9.2 \mathrm{M} \\
\mathrm{Pa}\end{array}$ & $9 \mathrm{MPa}$ & $10 \mathrm{MPa}$ & $10 \mathrm{MPa}$ \\
\hline
\end{tabular}

$\begin{array}{lllll}v & 0 & 0 & 0 & 0\end{array}$

0

The high porosity of the GDL (78\%) makes it possible to neglect the constraints arising from the variation of the moisture tau.

Table.3 GDL-TORAY-60 properties used in finite element analysis for GDL-TORAY-60

\begin{tabular}{cccc}
$\begin{array}{c}\text { Thickness } \\
(\mathrm{m})\end{array}$ & $\begin{array}{c}\text { Linear thermal } \\
\text { expansion Coefficient } \\
(1 / \mathrm{k})\end{array}$ & $\begin{array}{c}\text { Poisson's } \\
\text { coefficient }\end{array}$ & $\begin{array}{c}\text { Density } \\
\left(\mathrm{Kg} / \mathrm{m}^{3}\right)\end{array}$ \\
\hline $190 \mathrm{e}^{-6}$ & $-0.8 \mathrm{e}^{-6}$ & 0 & 450
\end{tabular}

\section{Hypothesis and boundary conditions}

With the hypothesis of associating the thermo-physical characteristics of the electrode with the GDL, viewed the small thickness of the electrode. In this case, we talk about what is called GDE (Gas diffusion Electrodes).. The mechanical characteristics are those adopted by J. Kleemann. 2009 [14] for linear orthotropic behavior of GDE. However, in case of non linear orthotropic of GDL, $\mathrm{E}_{\mathrm{y}}\left(\varepsilon_{\mathrm{y}}\right)$ was determined based on the empirical correlation (1), as well an imposed displacement can be deduced.

\section{Results and discussion}

A series of simulations were carried out on the model from low to high operating contact pressure between GDL and BP in order to evaluate the validity of our proposed model. Indeed, numerical simulations show comparative results in terms of the GDL intrusion predicted by five models under the standard conditions of assembly of the cell stack ( $\mathrm{T}=25^{\circ} \mathrm{C}$ and $\mathrm{RH}=90 \%$ ). According to the figure. 1 , in case of a contact pressure of $\mathrm{P}=3 \mathrm{MPa}$. It was found that the linear orthotopic model converges towards the experimental isotropic model of SG.Kandlikar et al. [8]. Negligible deviation from the non-linear orthotopic model of PAG. Salaberri [18] and Y. Lai [17] model is observed. However, a GDL intrusion gap in the channel ranging from $20 \mu \mathrm{m}$ to $30 \mu \mathrm{m}$ between the proposed nonlinear orthotopic model and those in the literature was observed. This implies that the non-linear orthotopic model underestimates the intrusion of GDL into the reactive gas channel, especially at medium contact pressure (P $=3 \mathrm{MPa}$ ).

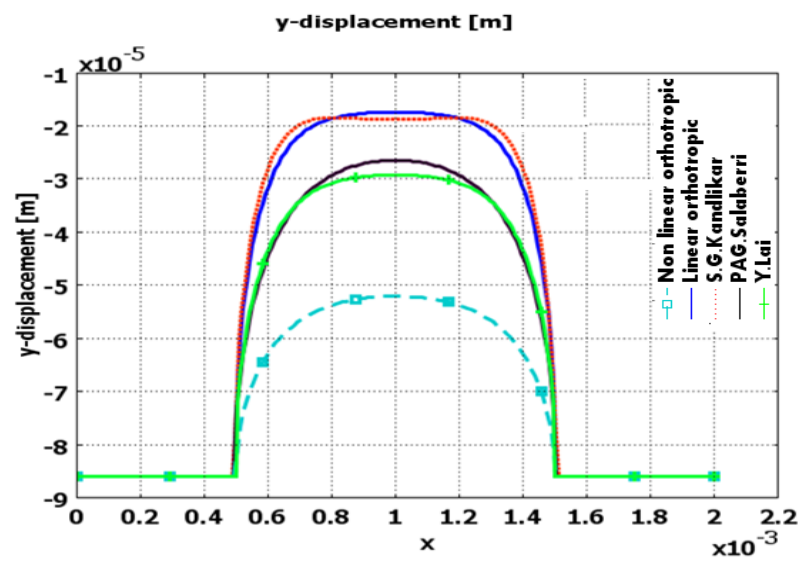

Figure.1 Comparison of the proposed model results with those of the literature at $\mathrm{P}=3 \mathrm{MPa}$ 


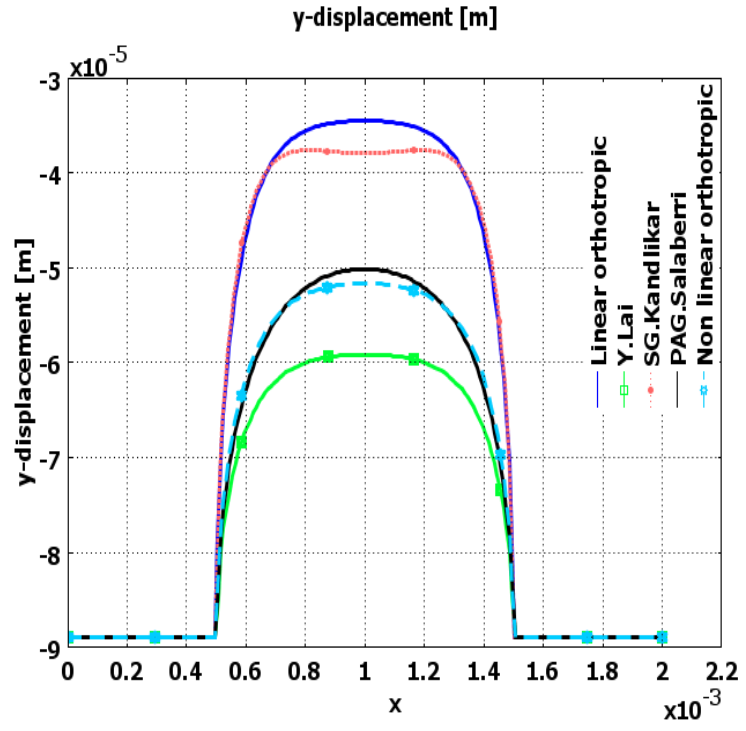

Figure.2 Comparison of the proposed model results with those of the literature at $\mathrm{P}=6 \mathrm{MPa}$

y-displacement [m]

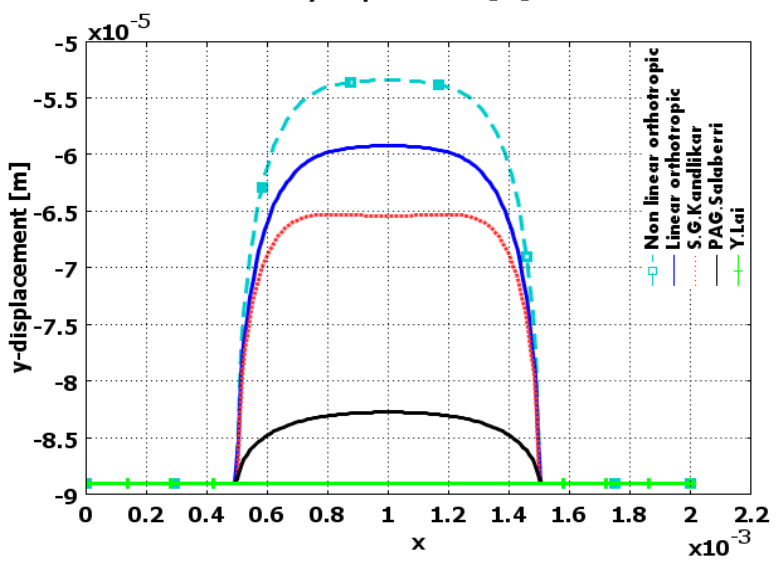

Figure.3 Comparison of the proposed model results with those of the literature at $\mathrm{P}=10 \mathrm{MPa}$

\section{Conclusion}

We have studied the influence of the contact pressure and the hygrothermal operating conditions on the the deformations of a typical unit of a PEMFC. Indeed, the clamping force exerted on the terminal bipolar plates induces an important contact pressure at the bipolar plate/GDL interface. This causes large deformations and strong stresses in the gas diffusers (GDL). The effect of relative humidity and operating temperature as well as the orthotopic behavior of GDL were put into effect in this study. We also investigated the intrusion of GDL into the membrane. Indeed,in the case of medium or high pressure, the two orthotropic models (linear and proposed nonlinear model) converge towards the models of the literature with negligible intrusion gaps. This leads to correct predictions in terms of interfacial contact pressure distribution of GDL and may lead to good predictions of reduction in reagent flow in the intrusive channel.

[1] Y. Faydi, R. Lachat, Y. Meyer,Thermomechanical characterisation of commercial Gas Diffusion Layersof a Proton Exchange Membrane Fuel Cell for high compressive pre-loadsunder dynamic excitation ,Fuel 182 (2016) 124-130

[2] Z. Zhang, Ph.D.Thesis, Modélisation mécanique des interfaces multi-contacts dans une pile à combustible , Université d'Évry-Val D’Essonne, 2010
[3] L. Shuo-Jen Lee, Chen-De Hsu, Ching-HanHuang, J. of Power Sources 145 (2005)353-361

[4] Jiabin Ge, Andrew Higier, Hongtan Liu, J.of Power Sources 159 (2006) 922-927

[5] R. Montanini, G.Squadrito, G.Giacoppo, Realization of a uniform internal stress distribution for each cell component is therefore essential, XIX IMEKO World Congress Fundamental and Applied Metrology, September 6-11, (2009)

[6] G. Maranzana, O. Lottin, T. Colinart, S. Chupin, S. Didierjean, A multiinstrumented polymer exchange membrane fuel cell: Observation of the in-plane nonhomogeneities, Journal of Power Sources, Vol. 180, $\mathrm{N}^{\circ} 2$, pp. 748-754, 2008

[7] S. Basu, J. Li, C. Y. Wang, Two-phase flow and mal distribution in gas channels of a polymer electrolyte fuel cell, Journal of Power Sources 187 (2009) 431-443

[8] SG.Kandlikar, Z. Lu , TY.Lin, D.Cooke, M.Daino,Uneven gasdiffusion layer intrusion in gas channel arrays of protonexchange membrane fuel cell and its effects on flowdistribution. J Power Sources2009; 194:328 37.

[9] Y. Tang, A. Karlsson, M. Santare., M. Gilbert, S .Cleghorn, W. Johnson, An experimental investigation of humidity and temperature effects on the mechanical properties of perfluorosulfonic acid membrane, J. Mater. Sci. 425 -297304, 2006

[10] A. Kusoglu, AM. Karlsson, M.Santare, S.Cleghorn , W.B.Johnson, $M$ echanical response of fuel cell membranessubjected to a hygro thermal cycle. J Power Sources 2006; 161: 98796

[11] P.Zhou, Wu CW, Ma GJ. Contact resistance prediction andstructure optimization of bipolar plates. J Power Sources2006; 159:1115 22.

[12] P. Zhou, C.W.Wu, J. Power Sources 170 (2007) 93-100.

[13] S.A. Freunberger, M. Reum, J. Evertz, A.Wokaun, F.N. Büchi, J. Electrochem. Soc.

[14] J. Kleemann , F. Finsterwalder, W. Tillmetz ,Characterization of mechanical behavior and coupledelectrical properties of polymer electrolyte membrane fuel cell gas diffusion layers, Journal of Power Sources, 190, 92-102, 2009.

[15] O.Kyeongmin, C.Purushothama, J.Hyunchul, Numerical study of thermal stresses in hightemperatureproton exchange membrane fuelcell (HT-PEMFC) "International journal of hydrogen energy39(2014) 2785e2794 39

[16] E. Sadeghi, N. Djilali, M. Bahrami, Effective thermal conductivity and thermal contact resistance of gas diffusion layers in proton exchange membrane fuel cells, Journal of Power Sources 196, 246-254, 2011

[17] YH.Lai Y, PA. Rapaport, C.Ji, V.Kumar, Channel intrusion of gas diffusion media and the effect on fuel cell performance. J.Power Sources 2008; 184:120 8.

[18] Pablo A. Garc1-Salaberri, Marcos Vera Ramon Zaera , ,Nonlinear orthotropic model of the inhomogeneous assembly compression of PEM fuel cell gas diffusion layers, International Journal of Hydrogen Energy 36(18):11856$11870 \cdot$ September 2011

[19] M. Mathias, J. Roth, J. Fleming, W. Lehnert. Chapter 46. In: Vielstich W, Gasteiger HA, Lamm A, editors. Handbook of fuel cells fundamentals, technology and applications. Fuelcell technology and applications, vol. 3. John Wiley \& Sons, Ltd; 2003. 